\title{
Extended-spectrum beta-lactamases screening agar with AmpC inhibition
}

\author{
N. Al Naiemi • J. L. Murk • P. H. M. Savelkoul • \\ C. M. J. Vandenbroucke-Grauls • \\ Y. J. Debets-Ossenkopp
}

Received: 17 January 2009 / Accepted: 30 January 2009/Published online: 20 February 2009

(C) The Author(s) 2009. This article is published with open access at Springerlink.com

The serious increase in the prevalence of extendedspectrum beta-lactamases (ESBLs) worldwide creates a need for effective and easy to perform screening methods for detection [1]. The use of an ESBL screening agar would allow rapid recognition and isolation of ESBL-producing bacteria. The currently available screening agars have low specificity, mainly due to growth of species with inducible AmpC beta-lactamases [2, 3]. The inhibition of AmpC beta-lactamases by cloxacillin is used in ESBL confirmation tests [4]; however, to the best of our knowledge, cloxacillin for ESBL screening has not been described. We developed an ESBL screening agar (ESA), which contains cloxacillin to inhibit growth of AmpC-producing species and vancomycin to inhibit growth of Enterococci, and compared it with the commercially available, selective medium for screening of presumptive ESBL Enterobacteriaceae, namely, BLSE agar (AES Laboratory, France).

The ESA consists of two MacConkey agars: one containing ceftazidime $1.0 \mathrm{mg} / \mathrm{l}$, and the other cefotaxime $1.0 \mathrm{mg} / \mathrm{l}$, cloxacillin $400 \mathrm{mg} / \mathrm{l}$, and vancomycin $64 \mathrm{mg} / \mathrm{l}$. The BLSE agar is a commercial double-plate agar (Mac-

\footnotetext{
J. L. Murk • P. H. M. Savelkoul •

C. M. J. Vandenbroucke-Grauls · Y. J. Debets-Ossenkopp Department of Medical Microbiology and Infection Control, VU University Medical Center,

Amsterdam, The Netherlands

N. Al Naiemi $(\bowtie)$

VU University Medical Center,

De Boelelaan 1117,

1081 HV Amsterdam, The Netherlands

e-mail: n.alnaiemi@vumc.nl
}

Conkey with ceftazidime $2 \mathrm{mg} / \mathrm{l}$ and Drigalski with cefotaxime $1.5 \mathrm{mg} / \mathrm{l}$ ). The combined screening with cefotaxime and ceftazidime has been shown to yield the best sensitivity and specificity for ESBL detection [5]. The concentration of cefotaxime and ceftazidime in ESA is consistent with the guidelines of the Clinical and Laboratory Standards Institute (CLSI) for screening of ESBLproducing Enterobacteriaceae [6] and with the guideline of the Dutch society for medical microbiology for screening and confirmation of ESBLs in Enterobacteriaceae (www. nvmm.nl). The inhibition of AmpC with cloxacillin depends on the concentration of cloxacillin in the agar (Fig. 1). Therefore, we evaluated the performance of ESA with different cloxacillin concentrations $(400,600,800$ and $1000 \mathrm{mg} / \mathrm{l}$ ), whereby $400 \mathrm{mg} / \mathrm{l}$ yielded the most optimal sensitivity.

The ESA and the BLSE agar were evaluated with 208 Enterobacteriaceae isolates, 70 of them were ESBLproducers (37 Escherichia coli, 10 Klebsiella spp., 1 Proteus mirabilis, 20 Enterobacter spp., 2 Citrobacter freundii) and 138 were ESBL negative (43 E. coli, 17 Klebsiella spp., 9 Proteus mirabilis, 55 Enterobacter spp., 6 Citrobacter freundii, 4 Morganella morganii, 1 Providencia spp., 3 Serratia spp.). These isolates had previously been genotypically characterized with PCR and subsequent sequence analysis with SHV, TEM and CTX-M primers for the bla $a_{\mathrm{SHV}}, b l a_{\mathrm{TEM}}$, and $b l a_{\mathrm{CTX}-\mathrm{M}}$ genes $[7,8]$. The media were incubated in air at $37^{\circ} \mathrm{C}$ for 18 to $24 \mathrm{~h}$. For negative cultures the incubation was prolonged for $48 \mathrm{~h}$.

The sensitivity and specificity of the ESA and the BLSE agar tested with the 208 Enterobacteriaceae isolates were $100 \%(70 / 70)$ and $84.7 \%(117 / 138)$, respectively, for the ESA, and $100 \%(70 / 70)$ and $57.2 \%(79 / 138)$ for the BLSE 
Fig. 1 AmpC inhibition with AmpC positive, ESBL negative. The increase in the zone around $\mathrm{AM}+\mathrm{CL}$ and CFOXT with addition of cloxacillin to the $\mathrm{MH}$ indicates the inhibition of AmpC. R, resistant; I, intermediate susceptible; $\mathrm{S}$, susceptible; AM+CL, amoxicillin-clavulanate; CFOXT, cefoxitin cloxacillin. Citrobacter freundii,

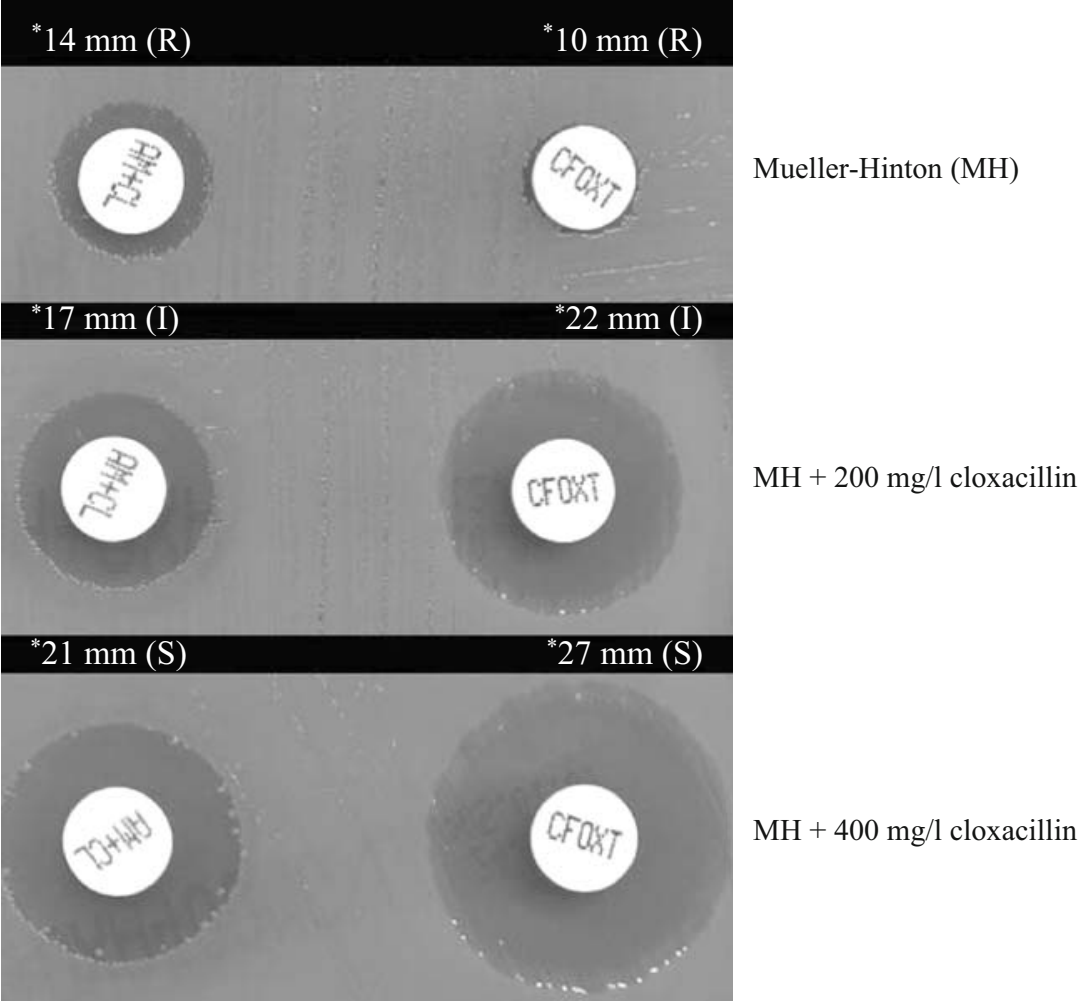

agar. The prolongation of incubation did not improve the sensitivity of the ESA or BLSE agars. The better performance of the ESA was mainly due to less false positive results due to AmpC-producing strains, especially Enterobacter spp. (false positive results for Enterobacter spp. with ESA was $29 \%$ or $16 / 55$ and with BLSE was $89 \%$ or 49/55). The specificity of ESA for screening of ESBLproducing strains was significantly better than the specificity of BLSE agar, which reduced the number of unnecessary confirmations. A quick and easy to use screening method to facilitate the detection of ESBLproducing Enterobacteriaceae in clinical settings is very important for optimal therapy and early application of appropriate infection control measures.

The ESA is, however, intended as a screening tool; therefore, it is important to note that any growth on the plates should not be taken as definitive proof of ESBL production, which can only be achieved by use of appropriate confirmatory tests. Despite the limitations of this preliminary study, our results show that ESA is a sensitive and convenient method to screen for ESBLproducing organisms. Further evaluation should be made with clinical specimens originating directly from human carries.

Open Access This article is distributed under the terms of the Creative Commons Attribution Noncommercial License which permits any noncommercial use, distribution, and reproduction in any medium, provided the original author(s) and source are credited.

\section{References}

1. Paterson DL, Bonomo RA (2005) Extended-spectrum betalactamases: a clinical update. Clin Microbiol Rev 18(4):657-686. doi:10.1128/CMR.18.4.657-686.2005

2. Glupczynski Y, Berhin C, Bauraing C, Bogaerts P (2007) Evaluation of a new selective chromogenic agar medium for detection of extended-spectrum beta-lactamase-producing Enterobacteriaceae. J Clin Microbiol 45(2):501-505. doi:10.1128/JCM.02221-06

3. Sturenburg E, Sobottka I, Laufs R, Mack D (2005) Evaluation of a new screen agar plate for detection and presumptive identification of Enterobacteriaceae producing extended-spectrum betalactamases. Diagn Microbiol Infect Dis 51(1):51-55. doi:10.1016/j. diagmicrobio.2004.08.009

4. Drieux L, Brossier F, Sougakoff W, Jarlier V (2008) Phenotypic detection of extended-spectrum beta-lactamase production in Enterobacteriaceae: review and bench guide. Clin Microbiol Infect 14 (Suppl 1):90-103. doi:10.1111/j.1469-0691.2007.01846.x

5. Hope R, Potz NA, Warner M, Fagan EJ, Arnold E, Livermore DM (2007) Efficacy of practised screening methods for detection of cephalosporin-resistant Enterobacteriaceae. J Antimicrob Chemother 59(1):110-113. doi:10.1093/jac/dk1431

6. Clinical and Laboratory Standards Institute (2007) Performance standards for antimicrobial susceptibility testing, seventeenth informational supplement. M100-S17. CLSI, Wayne, PA, USA

7. Al Naiemi N, Bart A, de Jong MD, Vandenbroucke-Grauls CM, Rietra PJ, Debets-Ossenkopp YJ, Wever PC, Spanjaard L, Bos AJ, Duim B (2006) Widely distributed and predominant CTX-M extended- spectrum beta-lactamases in Amsterdam, The Netherlands. J Clin Microbiol 44(8):3012-3014. doi:10.1128/JCM.01112-06 Vandenbroucke-Grauls CM, de Jong MD (2005) Widespread transfer of resistance genes between bacterial species in an intensive care unit: implications for hospital epidemiology. J Clin Microbiol 43(9):4862 4864. doi:10.1128/JCM.43.9.4862-4864.2005
8. Al Naiemi N, Duim B, Savelkoul PH, Spanjaard L, de Jonge E, Bart A, 